\title{
Lycium barbarum Polysaccharide Ameliorates Heat-Stress- Induced Impairment of Primary Sertoli Cells and the Blood-Testis Barrier in Rat via Androgen Receptor and Akt Phosphorylation
}

\author{
Suqin Hu $(\mathbb{D}$, Dianlong Liu, Sijia Liu, Chunrui Li, and Jian Guo \\ Department of Physiology, School of Traditional Chinese Medicine, Beijing University of Chinese Medicine, Beijing 100029, China \\ Correspondence should be addressed to Jian Guo; guojian@bucm.edu.cn
}

Received 15 February 2021; Revised 7 April 2021; Accepted 26 April 2021; Published 3 May 2021

Academic Editor: Harquin Simplice Foyet

Copyright (c) 2021 Suqin Hu et al. This is an open access article distributed under the Creative Commons Attribution License, which permits unrestricted use, distribution, and reproduction in any medium, provided the original work is properly cited.

\begin{abstract}
Male infertility induced by heat stress has been attracting more and more attention. Heat stress not only causes apoptosis of spermatocytes but also has adverse effects on Sertoli cells, further damaging spermatogenesis. Lycium barbarum polysaccharide (LBP) is the main bioactive component of Lycium barbarum, which has a protective effect on male reproduction, but its mechanism is still unclear. In this study, our results proved that LBP blocked the inhibitory effect on the proliferation activity of Sertoli cells after heat stress, reversed the dedifferentiation of Sertoli cells induced by heat stress, and ameliorated the structural integrity of the blood-testis barrier. In addition, it increased the expression of the androgen receptor and activated Akt signaling pathway to resist heat-stress-induced injury of Sertoli cells.
\end{abstract}

\section{Introduction}

More than half of the childbearing couples could not have children due to male infertility $[1,2]$, which is induced by varieties of causes including the spermatogenic quantitative or qualitative defect, catheter obstruction or dysfunction, and hypothalamic-pituitary axis disorders [3, 4]. Among these situations, abnormal spermatogenesis is the primary culprit of impaired male fertility. Spermatogenesis is a temperature-dependent process $[5,6]$. For most mammals, normal spermatogenesis entails the temperature in the scrotum to be lower than body temperature. After heat treatment to local testis, male animals display testicular damages, including local testis tissue hypoxia [7, 8], germ cells apoptosis [9], blood-testis barrier (BTB) dysfunction, and reduced sperm count and quality [10-12]. Thus, scrotal temperature increases and spermatogenesis is impaired, leading to male infertility.

Spermatogenesis depends on mature Sertoli cells (SCs). In the seminiferous tubule, SCs provide structural support and supply nutrients, functional proteins, and cytokines for spermatogenesis $[13,14]$. The number of SCs is proportional to the number of germ cells [15]. Occludin and zonula occludens-1 exist between adjacent SCs [16] and compose BTB which provides a suitable microenvironment for spermatogenesis $[17,18]$. The decrease of occludin and (or) zonula occludens- 1 causes the damage of BTB integrity, negatively effecting spermatogenesis $[15,19]$.

Androgen receptor (AR) is a type I steroid receptor. Androgens have to bind to AR before they can regulate the development of germ cells and SCs. Expressed in SCs, an androgen receptor (AR) plays a crucial role in spermatogenesis $[20,21]$. Studies demonstrated that the loss of AR directly influences the maturation and the final quantity of SCs [22, 23], as well as spermatogenesis [24]. Besides, the absence of AR causes increased permeability of BTB in vitro or in vivo $[25,26]$.

Lycium barbarum polysaccharide (LBP, PubChem SID: 134223164), the main component of Chinese wolfberry, is characterized by high bioactivity and significant content [27]. The glucoside apart, which is composed of arabinose, rhamnose, xylose, mannose, galactose, and glucose (Figure 1), accounts for more than $90 \%$ of the LBP mass [28]. Evidence shows LBP could ameliorate testicular damage by upregulating the testosterone level and reducing germ cell apoptosis [29-32]. However, limited research has been conducted on 
how LBP influences SCs and BTB. In the present study, we explore the effects and mechanisms of LBP on heat-stressinduced damage of SCs and BTB, centered around the changes in AR.

\section{Materials and Methods}

2.1. Drug and Reagents. Lycium barbarum polysaccharide powder was purchased from Nanjing Manhay Medical Technology (Nanjing, China, No. zhe B2-20090288-37).

DMEM/F12, $0.25 \%$ trypsin-ethylenediaminetetraacetic acid, collagenase IV, fetal bovine serum (FBS), and penicillin-streptomycin liquid were purchased from Gibco (BRL, Gaithersburg, MD, USA). 3-(4,5-Dimethylthiazol-2-yl)-2,5diphenyltetrazolium bromide (MTT), dimethyl sulfoxide (DMSO), phosphate buffered saline (PBS), and the bicinchoninic acid (BCA) protein assay kit were purchased from Solarbio Life Sciences (Beijing, China). SP link detection kits (biotin-streptavidin HRP detection systems) and the diaminobenzidine kit were purchased from ZSGB-BIO (Beijing, China). The anti-Ki67 (ab16667) and anti-AR (ab133273) were purchased from Abcam (Cambridge, UK). The antioccludin (PA5-20755) and anti-zonula occludens-1 (617300) were obtained from Thermo Fisher Scientific (Waltham, MA, USA). The anti-Phospho-Akt (Ser473) (\#4060) and anti-Akt (\#4691) were obtained from Cell Signaling Technology (Boston, MA, USA). The anti-CK-18 antibody (10830-1-AP) and anti-beta-actin antibody (60008-1-lg) were obtained from Proteintech (Chicago, IL, USA).

2.2. Animals. Mature male Sprague Dawley rats (8 weeks of age) were purchased from Huafukang (Beijing, China, No. SYXK Jing 2011-0024). These rats were treated and sacrificed according to the National Institutes of Health Guidelines for the Care and Use of Laboratory Animals (NIH Publication No. 85-23, revised 1985). All animal procedures were approved by the Laboratory Animal Welfare and Ethics Committee of the Beijing University of Chinese Medicine (BUCM-4-2017010805-010).

2.3. Primary SC Isolation, Culture, and Heat Treatment. Sertoli cell isolation was according to the previous method [33]. Briefly, the testicular tissue was obtained from the testis and washed twice in PBS precooled at $4^{\circ} \mathrm{C}$. After fully centrifuged at $1000 \mathrm{rmp}$ about $5 \mathrm{~min}$, the sediment was treated with collagenase IV $(0.5 \mathrm{mg} / \mathrm{mL})$ for $5 \mathrm{~min}$. After washing twice and certification for $5 \mathrm{~min}$, the sedimentation was secondly digested with trypsin $(0.05 \%)$ for $5 \mathrm{~min}$. FBS in the same velum was added to stop digestion. Then, the sedimentation was filtrated through a 100-mesh filter and centrifugated at $1000 \mathrm{rmp}$ for $5 \mathrm{~min}$. The cells were washed twice with DMEM/F12, collected in the culture medium (DMEM plus F12 with $10 \% \mathrm{FBS}$ and $1 \%$ penicillin-streptomycin), and cultured at $35^{\circ} \mathrm{C}$ in a $\mathrm{CO}_{2}$ incubator $\left(5 \% \mathrm{CO}_{2} /\right.$ $95 \%$ air). After $40 \mathrm{~h}$ culturing, the medium was replaced to remove unattached germ cells, and 12-24 h later, when cells were confluent, they were ready for the following experiments. LBP was dissolved and diluted with PBS into different concentrations and then was added in SCs at the dose of $25 \mathrm{mg} / \mathrm{L}, 50 \mathrm{mg} / \mathrm{L}$, and $100 \mathrm{mg} / \mathrm{L}$. Cells in the control group and heat-stress group were added with the same volume of PBS. After $24 \mathrm{~h}$, the control group was cultured at $35^{\circ} \mathrm{C}$ for another 20 minutes, and the other groups were treated in a $43^{\circ} \mathrm{C}$ water bath for 20 minutes.

2.4. Evaluation of Cell Viability. MTT assay has been widely used for measuring cell viability. The obtained absorbance value (OD value) under the specific wavelength is directly proportional to the number of living cells. SCs were seeded at $5 \times 104$ per well in 96 -well plates in DMEM/F12 supplemented with $10 \%$ FBS. Cells were treated with LBP in different concentrations or PBS for $24 \mathrm{~h}$. After removing some supernatant, an MTT regent $(5 \mathrm{mg} / \mathrm{ml})$ was added to each well for four hours. Then SCs were treated with DMSO by shaking for $15 \mathrm{~min}$ at room temperature, and the OD value was measured at $570 \mathrm{~nm}$ by using a microplate reader FLUO Star Omega (BMG Labtech, Offenburg, Germany). The blank group had no cells in wells and was used as the zero point of absorbance. Also, the absorbance value of each group divided by the control group was cell viability (\%).

2.5. Immunohistochemistry. The immunohistochemistry protocol in our experiment followed that described previously [34]. SCs were first fixed in a $4 \%$ polyoxymethylene solution and then treated with $0.5 \%$ triton $\mathrm{X}-100$ and $0.3 \%$ hydrogen peroxide, respectively. After three washes in PBS, cells were blocked with $10 \%$ goat serum to suppress the nonspecific antigen and then incubated in the primary antibody of Ki67 $(1: 200)$ or AR $(1: 200)$ overnight at $4^{\circ} \mathrm{C}$. The next day, after three washes in PBS, the biotinylated secondary antibodies were added for $15 \mathrm{~min}$ at $37^{\circ} \mathrm{C}$. After three washes in PBS, the horseradish enzyme labeling streptavidin working solution was added for $15 \mathrm{~min}$ at $37^{\circ} \mathrm{C}$. Immunostaining was developed with the diaminobenzidine kit and counterstained with hematoxylin. Six nonoverlapping fields were selected for each group to take pictures. Image-Pro Plus (Version 6.0, Media Cybernetics, Bethesda, MD, USA) software was used to process the images and count the positive cells for statistical analysis.

2.6. Western Blot. Western blot was performed as described previously $[35,36]$. The total protein was extracted from SCs and transferred to polyvinyl difluoride (PVDF) membranes. PVDF membranes were blocked in 5\% nonfat milk for $1 \mathrm{~h}$ at room temperature and then exposed to the primary antibodies diluted in $1 \%$ blocking buffer: AR $(1: 1000), \mathrm{CK}-18$ (1:1000), occludin $(1: 1000)$, zonula occludens-1 $(1: 1000)$, p-Akt (Ser473) $(1: 1000)$, and Akt $(1: 1000)$ at $4^{\circ} \mathrm{C}$ overnight. After washing in tris-buffered saline containing $0.1 \%$ Tween20 (TBST) three times, the membranes were incubated in horseradish-peroxidase- (HRP-) conjugated second antibodies $(1: 4000)$ for $1 \mathrm{~h}$. After washing with TBST, the membranes were visualized by a hypersensitive electrogenerated chemiluminescence solution (Proteintech). $\beta$-Actin (1:5000) was used as an internal control for AR, 
<smiles>OC1OC[C@@H](O)[C@H](O)[C@H]1O</smiles>

(a)

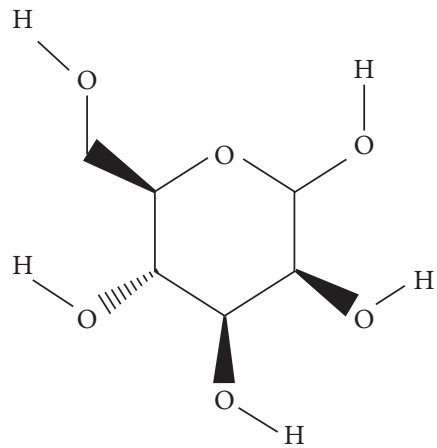

(d)<smiles>C[C@@H]1OC(O)[C@@H](O)[C@@H](O)[C@@H]1O</smiles>

(b)

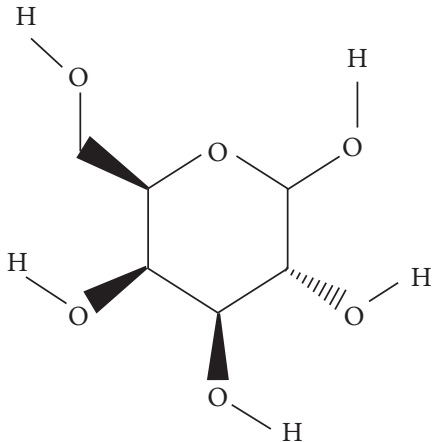

(e)<smiles>OC1OC[C@@H](O)[C@H](O)[C@H]1O</smiles>

(c)

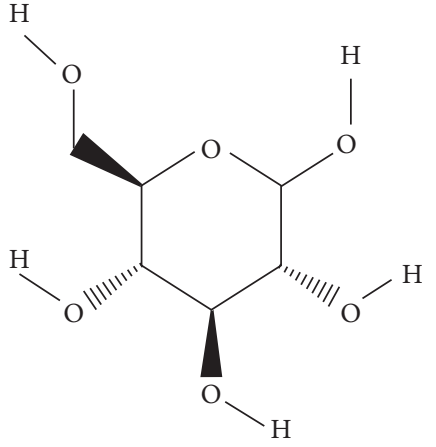

(f)

Figure 1: Six main monosaccharides in LBP. (a) Arabinose (PubChem CID: 439195); (b) rhamnose (PubChem CID: 25310); (c) xylose (PubChem CID: 135191); (d) mannose (PubChem CID: 18950); (e) galactose (PubChem CID: 6036); and (f) D-glucose (PubChem CID: 5793).

CK-18, occluding, and zonula occludens-1. Akt was used as an internal control for phosphorylated-Akt in Ser473. Band intensities were determined by the software Quantity One, Version 4.6.2 (Bio-Rad Laboratories, Hercules, CA, USA).

2.7. Statistical Analysis. Each experiment was repeated at least three times. Statistical analysis was performed with the software SPSS version 20.0 (IBM, Albuquerque, NY, USA). Data that conformed to normal distribution or approximate normal distribution are expressed as means \pm standard error of the mean (SEM). One-way analysis of variance was used for analyzing the data in different groups, and the pairwise comparisons were tested by the Tukey multiple comparison test. $P<0.05$ was considered as significant, and $P<0.01$ was considered as highly significant.

\section{Results}

3.1. The Changes in Cell Viability of SCs after Different Concentrations of LBP Treatment. To observe the effect of LPB on cell viability and select appropriate drug concentrations, we detected the OD value by MTT. As shown in Figure 2, compared with the control group, the cell viability of SCs at $25 \mathrm{mg} / \mathrm{L}, 50 \mathrm{mg} / \mathrm{L}$, and $100 \mathrm{mg} / \mathrm{L} \mathrm{LBP}$ treatment groups significantly increased $(P<0.05$ or $P<0.01)$, while the differences in other LBP groups were not statistically significant $(P>0.05)$. Therefore, these three concentrations were selected as the concentration of LBP drug groups.

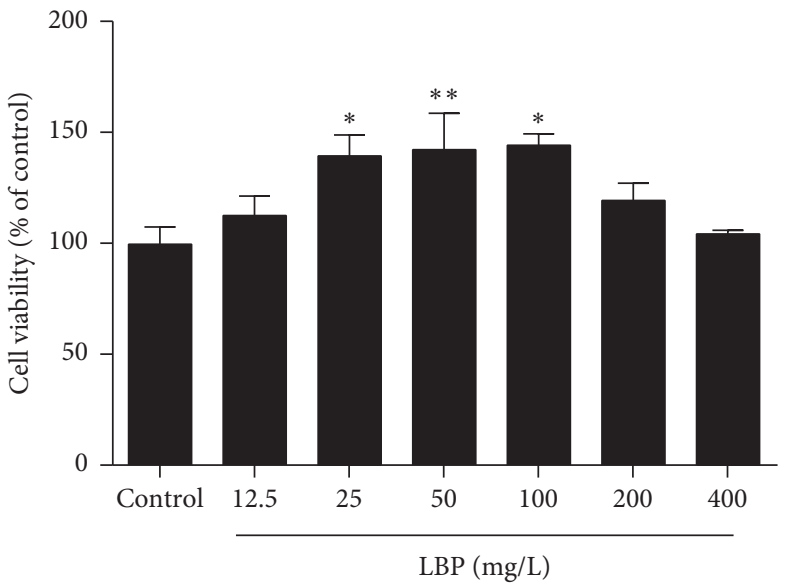

FIGURE 2: The changes of cell viability of SCs after different concentrations of LBP treatment. After treatment of LBP at $25 \mathrm{mg} / \mathrm{L}$, $50 \mathrm{mg} / \mathrm{L}$, and $100 \mathrm{mg} / \mathrm{L}$, the cell viability of SCs was obviously increased. Data are presented as means $\pm \operatorname{SEM}(n=3)$ from three independent experiments. ${ }^{*} p<0.05$ and ${ }^{* *} p<0.01$, compared to the control group.

3.2. LBP Alleviates the Decrease of SC Proliferation Activity after Heat Stress. To investigate the effect of LBP on the proliferation activity of SCs after heat stress, we tested the Ki67 in SCs (Figure 3). Ki67 expresses in the SCs nucleus. Compared with the control group, the positive signal of Ki67 significantly decreased in the heat-stress group and $25 \mathrm{mg} / \mathrm{L}$ 

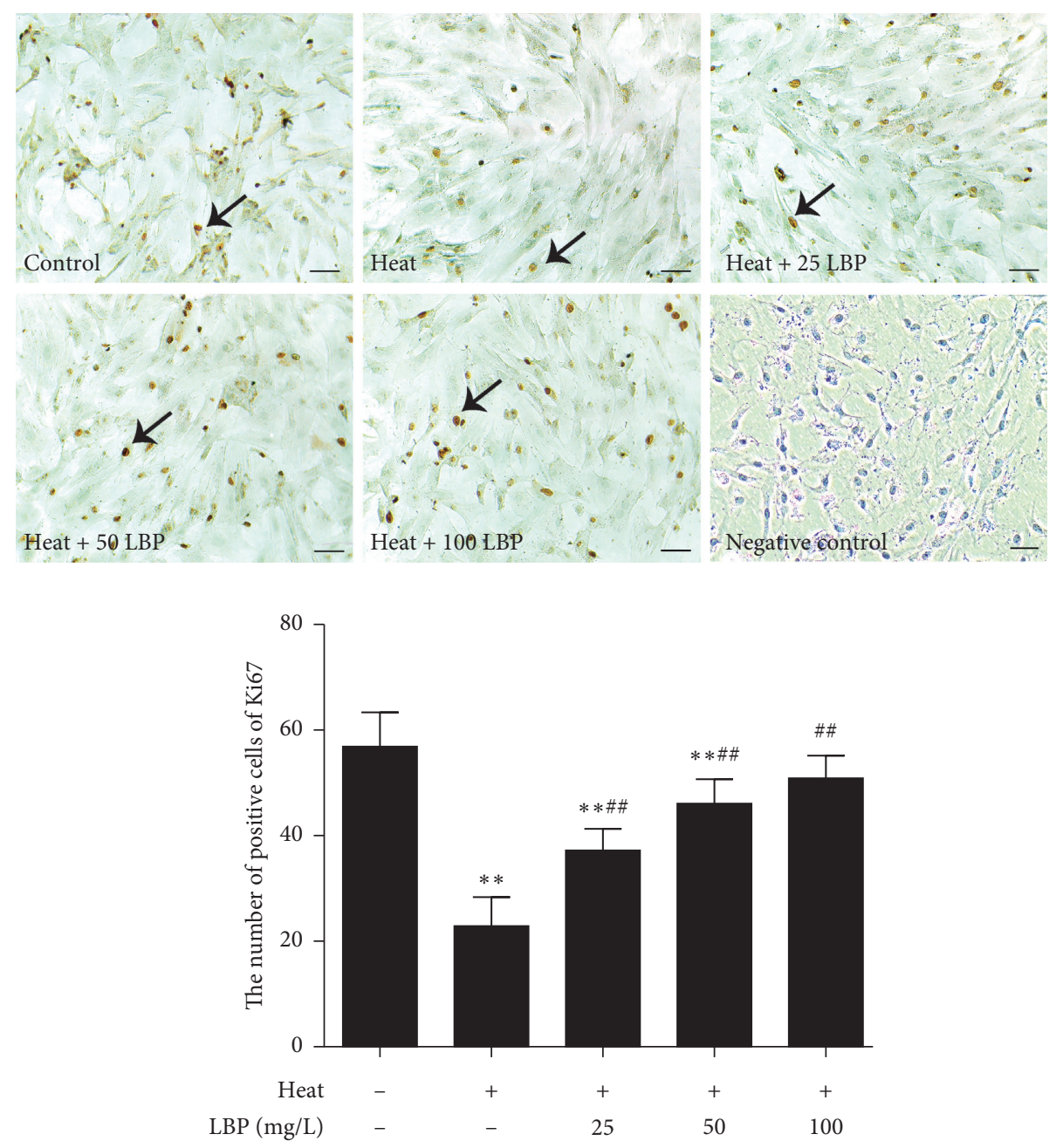

FIgURE 3: LBP improves the proliferation activity of SCs after heat stress. The expression of Ki67 was observed with the immunohistochemical assay. Scale bar: $50 \mu \mathrm{m}$. The brown areas are Ki67 positive Sertoli cells (black arrows). Data are presented as means \pm SEM $(n=3)$ from three independent experiments. ${ }^{* *} p<0.01$, compared to the control group. ${ }^{\#} p<0.01$, compared to the heat-stress group.

LBP group $(P<0.05$ or $P<0.01)$, and the $50 \mathrm{mg} / \mathrm{L} \mathrm{LBP}$ and $100 \mathrm{mg} / \mathrm{L}$ LBP group have no significant change. Compared with the heat-stress group, the positive signal of $\mathrm{Ki} 67$ in LBP treatment groups showed a noticeable increase $(P<0.01)$. These data indicated that LBP treatment could resist the reduction of $\mathrm{Ki} 67$ expression induced by heat stress; however, the $25 \mathrm{mg} / \mathrm{L}$ LBP group still had a noticeable difference compared to the control group, and $50 \mathrm{mg} / \mathrm{L} \mathrm{LBP}$ and $100 \mathrm{mg} / \mathrm{L} \mathrm{LBP}$ could improve the proliferation activity of SCs after heat stress to the level of normal statement.

3.3. LBP Inhibits the Dedifferentiation of SCs after Heat Stress. To observe the effect of LBP on the differentiation of SCs, we tested the expression of CK-18 (Figure 4). The expression of CK-18 in the heat-stress group significantly increased $(P<0.05$ or $P<0.01)$ when compared with the control group. Moreover, compared with the heat-stress group, the expression of CK-18 in LBP treatment groups (25, 50 , and $100 \mathrm{mg} / \mathrm{L})$ decreased significantly $(P<0.01)$.
3.4. LBP Maintains the Integrity of BTB after Heat Stress. To clarify the effect of LBP on BTB, we detected the TJ-associated protein, occludin (Figure 5(a)) and zonula occludens-1 (Figure 5(b)). As shown in Figure 5, compared with the control group, the expression of occludin and zonula occludens- 1 in the heat-stress group significantly decreased $(P<0.05$ or $P<0.01)$. Compared with the heat-stress group, the expression of occludin and zonula occludens-1 in LBP treatment groups increased significantly $(P<0.01)$ in a dosedependent manner $(P<0.05$ or $P<0.01)$.

3.5. LBP Maintains the Expression of AR in SCs after Heat Stress. Testosterone only works when combining to the androgen receptor. To determine the AR in SCs and to better understand the mechanism of AR, we analyzed AR with immunohistochemistry staining (Figure 6(a)) and western blot (Figure 6(b)). Figure 6(a) shows that AR mainly expresses in the nucleus and few are expressed in the cytoplasm of mature SCs. As shown in Figure 6, the expression of AR did significantly decrease $(P<0.01)$ after heat treatment. 

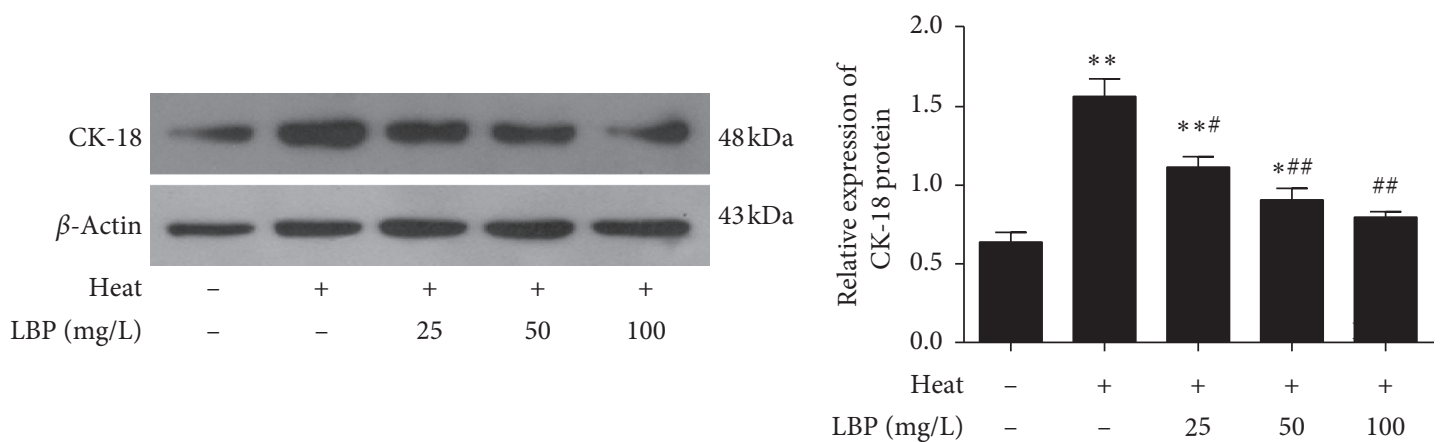

FIGURE 4: LBP inhibits the dedifferentiation of SCs after heat stress. CK-18 was checked by western blot. Data are presented as means \pm SEM $(n=3)$ from three independent experiments. ${ }^{*} p<0.05$ and ${ }^{* *} p<0.01$, compared to control group. ${ }^{\#} p<0.05$ and ${ }^{\# \#} p<0.01$, compared to the heat-stress group.
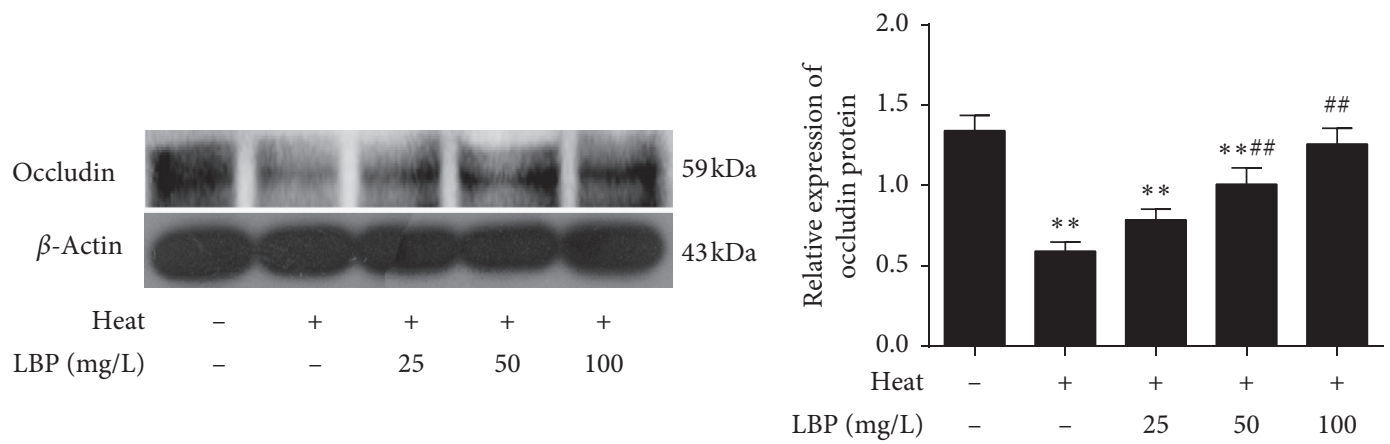

(a)
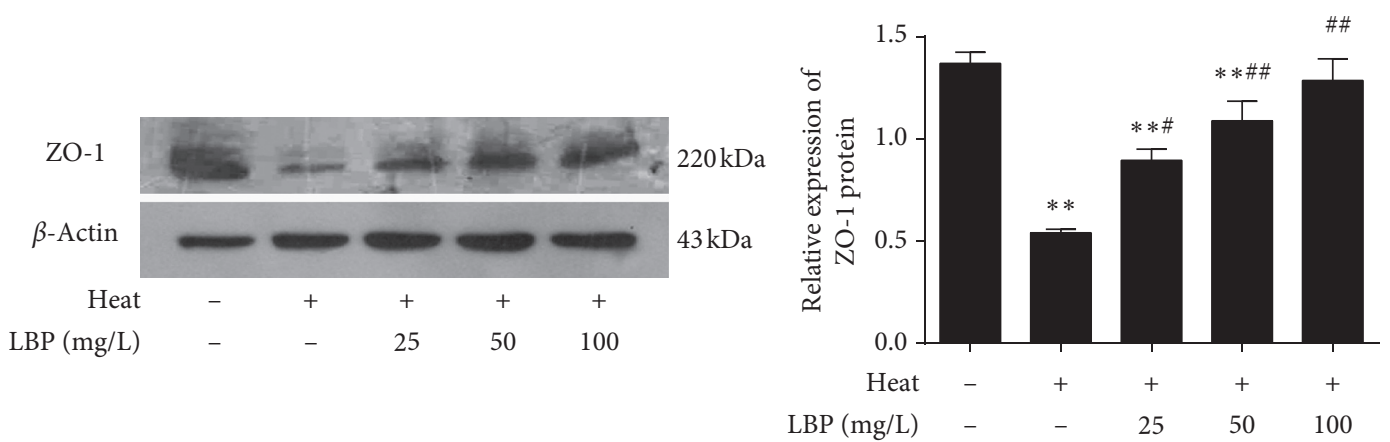

(b)

Figure 5: LBP maintains the integrity of BTB after heat stress. Occludin and ZO-1 in SCs were detected with western blot (a, b). Data are presented as means $\pm \operatorname{SEM}(n=3)$ from three independent experiments. ${ }^{* *} p<0.01$, compared to the control group. ${ }^{\#} p<0.05$, ${ }^{\# \#} p<0.01$, compared to the heat-stress group.

Compared with the heat-stress group, the expression of AR in LBP treatment groups increased significantly $(P<0.01)$.

\subsection{LBP Maintains the Akt Phosphorylation in SCs after Heat} Stress. We all know the critical role of the Akt signaling pathway in cell activity. It has been found that there is an interaction between AR and Akt phosphorylation at Ser473 [37]. Consequently, we tested the expression of p-Akt (Ser473) to explore the effective way of LBP on SCs (Figure 7). Compared with the control group, the expression of p-Akt (Ser473) in the heat-stress group significantly decreased $(P<0.01)$. Compared with the heat-stress group, the expression of p-Akt (Ser473) in
LBP treatment groups increased significantly $(P<0.01)$. These data indicated that Akt phosphorylation at Ser473 was involved in the protective effect of LBP on SCs and BTB.

\section{Discussion}

Sertoli cells are the most crucial somatic cells for spermatogenesis. The number and maturations of SCs determine the spermatogenesis. In this study, our data indicate that LBP could resist the decrease of proliferation activity, inhibit the dedifferentiation of SCs after heat stress, and more importantly, preserve BTB integrity and permeability by maintaining AR and phosphorylated-Akt (Ser473). 


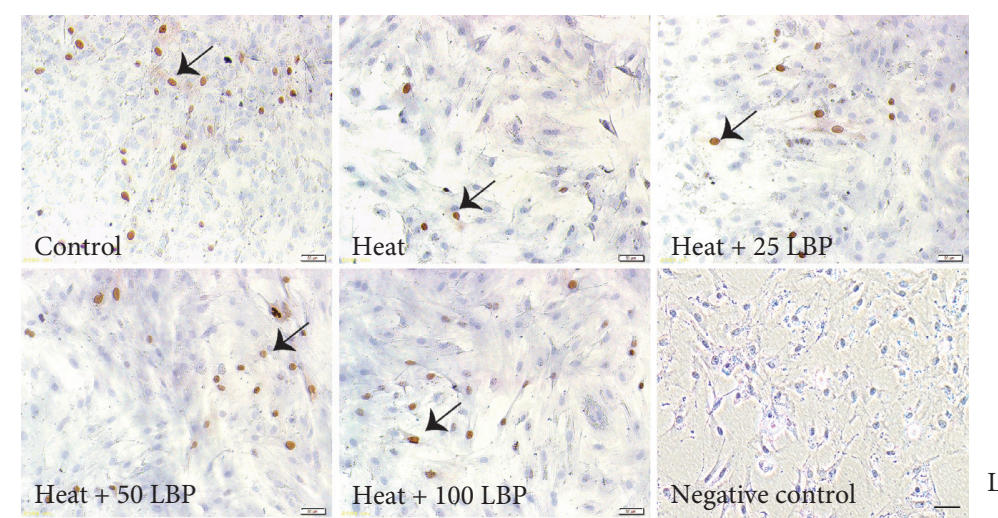

(a)

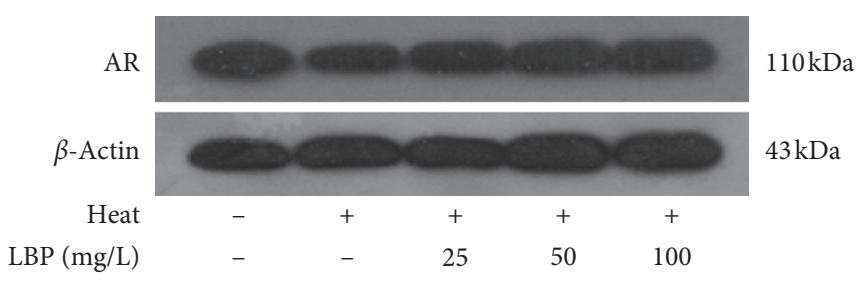

(b)
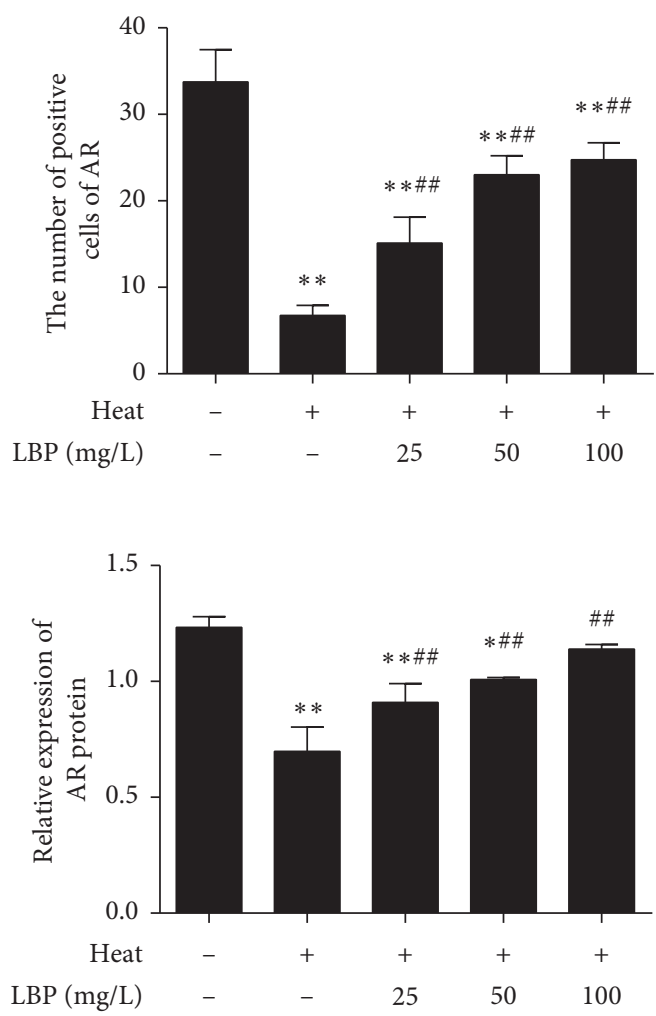

LBP $(\mathrm{mg} / \mathrm{L}) \quad-\quad-\quad-\quad 25 \quad 50 \quad 100$

FIGURE 6: LBP upregulates the expression of AR in SCs after heat stress. The expression of AR was observed by immunohistochemical assay (scale bar: $50 \mu \mathrm{m}$ ) and western blot (b). The brown areas are AR-positive Sertoli cells (black arrows). Data are presented as means \pm SEM $(n=3)$ from three independent experiments. ${ }^{*} p<0.05$ and ${ }^{* *} p<0.01$, compared to the control group. ${ }^{\# \#} p<0.01$, compared to the heatstress group.
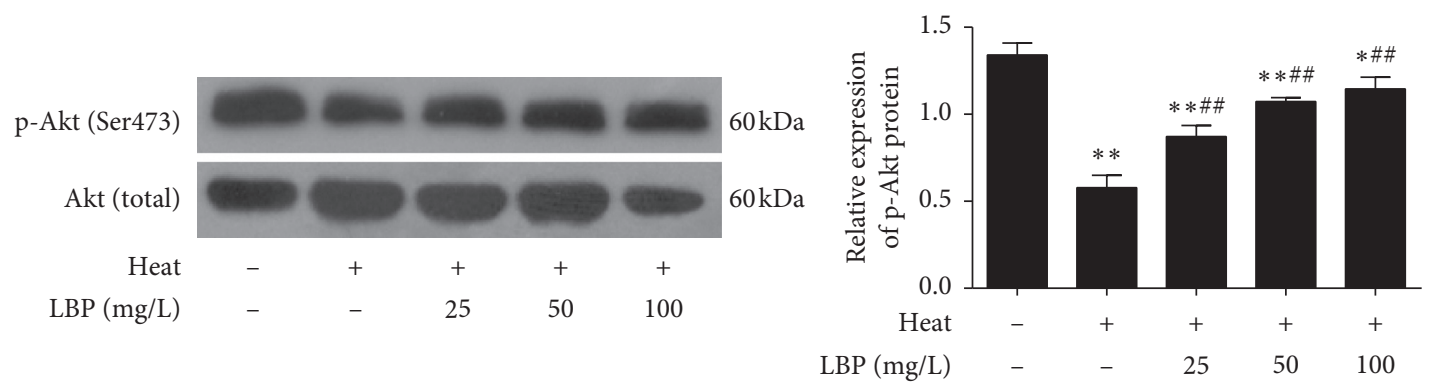

Figure 7: LBP promotes the Akt phosphorylation in SCs after heat stress. The phosphorylated Akt was detected with western blot. Data are presented as means $\pm \operatorname{SEM}(n=3)$ from three independent experiments. ${ }^{*} p<0.05$ and ${ }^{* *} p<0.01$, compared to the control group. ${ }^{\# \#} p<0.01$, compared to the heat-stress group.

Lycium barbarum fruits, as a traditional Chinese medicine and health food for people, have been used to nourish the kidney and improve fertility for thousands of years $[38,39]$. The polysaccharide is the primary active component responsible for those biological activities in L. barbarum fruits [28]. Also, LBP has been reported to possess a wide range of pharmacological activities, including antioxidant, anticancer, and neuroprotective effects, immune regulation, and others [40]. Recently, there are some reports about the effects of LBP on male fertility, for example, increasing the serum testosterone level and decreasing apoptosis of germ cells. However, the effects of LBP on SCs and BTB are rarely reported. Thus, this study intends to investigate the effects and underlying mechanisms of LBP on SCs and BTB.

Temperature is an essential controller for reproductive activity and testicular homeostasis [41]. Only can physiological scrotal hypothermia guarantee the normal spermatogenesis in most mammals [42]. Despite that SCs are more tolerant to heat than germ cells, heat stress still can cause damaged structure and dysfunction of SCs [43], 


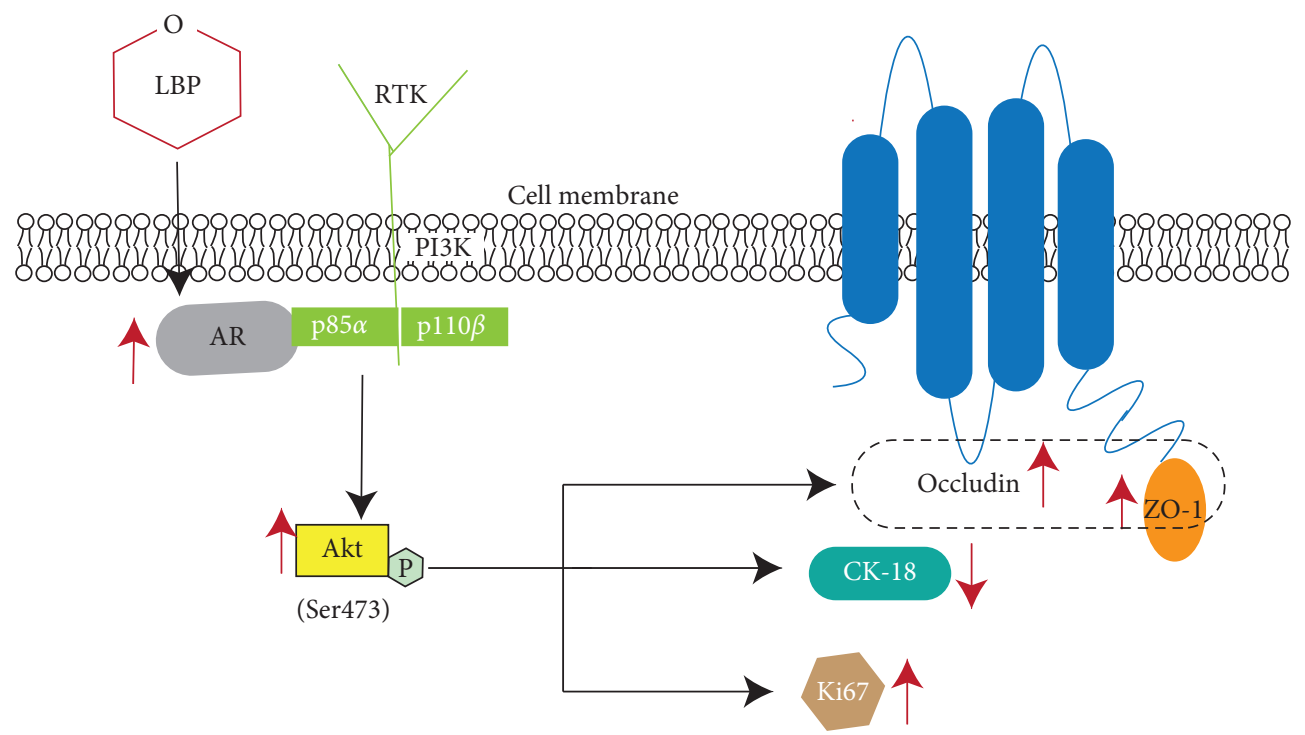

FIGURE 8: Effects and mechanism of LBP on Sertoli cells and BTB after heat stress. AR could directly interact with PI3K regulatory subunit p $85 \alpha$ to activate kinase Akt [37, 73]. LBP maintained the expression of Ki67 and TJ protein and suppressed the re-expression of CK-18 by resisting the decrease of $\mathrm{AR}$ and maintaining phosphorylation of Akt in Sertoli cells after heat stress.

resulting in spermatogenic arrest and weak fertilizing capacity in vivo and in vitro $[10,44]$. Some evidence and our previous study proved that local testis heat treatment $\left(43^{\circ} \mathrm{C}\right.$ for $20 \mathrm{~min}$ ) successfully leads to dyszoospermia of monkey and rodents $[33,45,46]$. Furthermore, compared with other modeling methods of spermatogenesis disorder, heat-stressinduced impairment on testis is reversible, which is very suitable to study the sequence and interaction between SCs and germ cells.

We first selected three suitable concentrations of LBP by MTT (Figure 2) to treat Sertoli cell. As we previously said, the number of SCs directly determines the number of sperm. Ki67, a nuclear antigen closely related to cell mitosis, is often considered as a marker of cell proliferative activity [47, 48]. For rat SCs, the number of SCs keeps increasing after birth, as well as the number of $\mathrm{Ki} 67$ positive cells, while it began to decline at the age of 90 days [49], which suggest SCs of 60-day-old rats are not fully mature and some of them still can proliferate. Intervention on SCs of 60-day-old rats can affect the final number of SCs in seminiferous tubules. Therefore, we detected the expression of Ki67 to observe the proliferation activity of SCs. The result confirmed that LBP could preserve the cell proliferative activity of SCs after heat stress (Figure 3). Furthermore, only mature SCs can support spermatogenesis. CK18 is a cytoskeleton molecule, which expresses in the prepubertal SCs and gradually disappears after puberty on mammals [50, 51]. High expression of CK-18 indicates that SCs are immature and dysfunctional [52]. Our results imply that LBP treatment could inhibit the re-expression of CK-18 after heat stress (Figure 4) to prevent the dedifferentiation of SCs.

The formation of BTB occurs at the beginning of puberty, and BTB is partly composed of tight junction (TJ), which directly affects the permeability [53]. Occludin is a highly phosphorylated transmembrane TJ-associated protein [54], believed as the initiator of BTB formation [55], and it is related to the initiation of spermatogenesis as well $[56,57]$. Zonula occludens-1, a peripheral transmembrane protein, forms a link between the transmembrane proteins and the cytoskeletal compartment $[58,59]$ to maintain the integrity of BTB and support the migration and release of germ cells [60]. Reports have shown that increased permeability and dysfunction of BTB are blamed for the loss of occludin and (or) zonula occludens-1, resulting in harmful influence to spermatogenesis $[61,62]$. Therefore, we selected occludin and zonula occludens-1 as the molecule marker of BTB integrity. Our data indicated that LBP could maintain the expression of them in SCs to ameliorate the heat-stress-induced increasing permeability and dysfunction of BTB (Figure 5).

It is well known that testosterone and AR are the decisive factors for maintaining male fertility and secondary sexual characteristics. AR is believed as a crucial upstream factor in controlling the development of SCs and the forming of BTB [63]. AR deficiency caused failure of SCs maturation [64] and decrease of TJ-associated protein expression [10, 11, 65]. In the present study, our data demonstrated that LBP could against the decrease of AR induced by heat stress, which was consistent with the change of tight junction protein, but opposite to CK-18 (Figure 6). Furthermore, through in vivo experiments, it was found that LBP increased the serum testosterone level in rats. We concluded the increase of testosterone and AR can improve their binding efficiency, which may be an important reason for LBP to ameliorate heat-stress-induced damage of SCs dedifferentiation and increase of BTB integrity and permeability.

Akt/protein kinase $\mathrm{B}(\mathrm{PKB})$, a serine/threonine kinase, is a mediator in the growth and proliferation of Sertoli cells $[66,67]$. Akt is activated by phosphorylation on threonine 308 (Thr308) and serine 473 (Ser473), with phosphorylation at Ser473 resulting in maximal Akt activity [68]. Upregulated 
Akt phosphorylation could promote the expression of Ki67 [69]. Besides, studies showed that the Akt signaling pathway is related to the expressions of occludin and zonula occludens-1 [70, 71], and activation of Akt by enhancing phosphorylation of p-Akt (Thr308) and p-Akt (Ser473) can effectively prevent the destruction of the TJ barrier [72]. Also, after blocking the Akt signaling pathway, AR transduction was blocked into the testosterone signaling pathway in SCs, and Akt phosphorylation at Ser473 is the key molecule in the pathway of AR trafficking [37, 73]. In our results, the expression p-Akt (Ser473) of heat-stress SCs decreased while it increased after LBP treatment (Figure 7), as well as AR. Therefore, we concluded that the Akt signaling pathway involves in the effect of LBP on ameliorating heatstress-induced damages in SCs and BTB.

In summary, our study indicates that LBP can preserve the expression of Ki67 and occludin and zonula occludens1 and inhibit the expression of CK-18 to prevent heatstress-induced impairment of Sertoli cells and BTB through maintaining $\mathrm{AR}$ and Akt phosphorylation at Ser473 (Figure 8). Also, it provides the experimental evidence for clinical prevention of male reproductive heatstress injury.

\section{Data Availability}

The data supporting the conclusions of this article are included within the article.

\section{Conflicts of Interest}

The authors declare that they have no conflicts of interest.

\section{Authors' Contributions}

Jian Guo conceived of the study and directed the work; Suqin $\mathrm{Hu}$ performed the experiments; Dianlong Liu, Sijia Liu, and Chunrui Li also contributed to the experiments; Suqin Hu drafted the manuscript; Jian Guo made the critical revisions and improvements for the manuscript; and Suqin $\mathrm{Hu}$ and Jian Guo finalized the paper.

\section{Acknowledgments}

This research was supported by grants from the National Natural Science Foundation of China (81273610) and Research and Development Fund of Beijing University of Chinese Medicine (2019-ZFXZJJ-021).

\section{References}

[1] D. de Kretser, "Male infertility," The Lancet, vol. 349, no. 9054, pp. 787-790, 1997.

[2] P. Thonneau, S. Marchand, A. Tallec et al., "Incidence and main causes of infertility in a resident population $(1,850,000)$ of three French regions (1988-1989)*," Human Reproduction, vol. 6, no. 6, pp. 811-816, 1991.

[3] H. Tournaye, C. Krausz, and R. D. Oates, "Novel concepts in the aetiology of male reproductive impairment," The Lancet Diabetes \& Endocrinology, vol. 5, no. 7, pp. 544-553, 2017.
[4] E. Babakhanzadeh, M. Nazari, S. Ghasemifar, and A. Khodadadian, "Some of the factors involved in male infertility: a prospective review," International Journal of General Medicine, vol. 13, pp. 29-41, 2020.

[5] Y.-X. Liu, "Control of spermatogenesis in primate and prospect of male contraception," Archives of Andrology, vol. 51, no. 2, pp. 77-92, 2005.

[6] A. Garolla, M. Torino, B. Sartini et al., "Seminal and molecular evidence that sauna exposure affects human spermatogenesis," Human Reproduction, vol. 28, no. 4, pp. 877-885, 2013.

[7] R. J. Aitken and S. D. Roman, "Antioxidant systems and oxidative stress in the testes," Advances in Experimental Medicine and Biology, vol. 636, pp. 154-71, 2008.

[8] J. G. Reyes, J. G. Farias, S. Henriquez-Olavarrieta et al., "The hypoxic testicle: physiology and pathophysiology," Oxidative Medicine and Cellular Longevity, vol. 2012, Article ID 929285 , 15 pages, 2012.

[9] S. Kaur and M. P. Bansal, "Protective role of dietary-supplemented selenium and vitamin $\mathrm{E}$ in heat-induced apoptosis and oxidative stress in mice testes," Andrologia, vol. 47, no. 10, pp. 1109-1119, 2015.

[10] M. Chen, H. Cai, J.-L. Yang et al., "Effect of heat stress on expression of junction-associated molecules and upstream factors androgen receptor and Wilms' tumor 1 in monkey sertoli cells," Endocrinology, vol. 149, no. 10, pp. 4871-4882, 2008.

[11] X. X. Li, S. R. Chen, B. Shen et al., "The heat-induced reversible change in the blood-testis barrier (BTB) is regulated by the androgen receptor (AR) via the partitioning-defective protein (par) polarity complex in the mouse," Biology of Reproduction, vol. 89, no. 1, p. 12, 2013.

[12] J. M. Bedford, "Human spermatozoa and temperature: the elephant in the room," Biology of Reproduction, vol. 93, p. 97, 2015.

[13] L. Rato, S. Socorro, J. E. B. Cavaco, and P. F. Oliveira, "Tubular fluid secretion in the seminiferous epithelium: ion transporters and aquaporins in sertoli cells," The Journal of Membrane Biology, vol. 236, no. 2, pp. 215-224, 2010.

[14] M. D. Griswold, "Interactions between germ cells and sertoli cells in the testis," Biology of Reproduction, vol. 52, no. 2, pp. 211-216, 1995.

[15] W.-Y. Lui, W. M. Lee, and C. Y. Cheng, "Transforming growth factor- $\beta 3$ perturbs the inter-sertoli tight junction permeability barrier in vitro possibly mediated via its effects on occludin, zonula occludens-1, and claudin-111," Endocrinology, vol. 142, no. 5, pp. 1865-1877, 2001.

[16] G. A. Tarulli, S. J. Meachem, S. Schlatt, and P. G. Stanton, "Regulation of testicular tight junctions by gonadotrophins in the adult Djungarian hamster in vivo," Reproduction, vol. 135, no. 6, pp. 867-877, 2008.

[17] N. Lee, E. Wong, D. Mruk, and C. Cheng, "Testicular cell junction: a novel target for male contraception," Current Medicinal Chemistry, vol. 16, no. 7, pp. 906-915, 2009.

[18] P. G. Stanton, "Regulation of the blood-testis barrier," Seminars in Cell \& Developmental Biology, vol. 59, pp. 166-173, 2016.

[19] C. Fink, R. Weigel, T. Hembes et al., "Altered expression of ZO-1 and ZO-2 in sertoli cells and loss of blood-testis barrier integrity in testicular carcinoma in situ," Neoplasia, vol. 8, no. 12, pp. 1019-1027, 2006.

[20] M. E. Baker, "Steroid receptor phylogeny and vertebrate origins," Molecular and Cellular Endocrinology, vol. 135, no. 2, pp. 101-107, 1997. 
[21] R.-S. Wang, S. Yeh, L.-M. Chen et al., "Androgen receptor in sertoli cell is essential for germ cell nursery and junctional complex formation in mouse testes," Endocrinology, vol. 147, no. 12, pp. 5624-5633, 2006.

[22] E. Enmark and J. A. Gustafsson, "Orphan nuclear receptors-the first eight years," Molecular Endocrinology, vol. 10, no. 11, pp. 1293-1307, 1996.

[23] R. Hazra, L. Corcoran, M. Robson et al., "Temporal role of sertoli cell androgen receptor expression in spermatogenic development," Molecular Endocrinology, vol. 27, no. 1, pp. 12-24, 2013.

[24] S. Yeh, M.-Y. Tsai, Q. Xu et al., "Generation and characterization of androgen receptor knockout (ARKO) mice: an in vivo model for the study of androgen functions in selective tissues," Proceedings of the National Academy of Sciences, vol. 99, no. 21, pp. 13498-13503, 2002.

[25] A. Florin, M. Maire, A. Bozec et al., "Androgens and postmeiotic germ cells regulate claudin-11 expression in rat sertoli cells," Endocrinology, vol. 146, no. 3, pp. 1532-1540, 2005.

[26] J. Meng, R. W. Holdcraft, J. E. Shima, M. D. Griswold, and R. E. Braun, "Androgens regulate the permeability of the blood-testis barrier," Proceedings of the National Academy of Sciences, vol. 102, no. 46, pp. 16696-16700, 2005.

[27] W. Liu, Y. Liu, R. Zhu et al., "Structure characterization, chemical and enzymatic degradation, and chain conformation of an acidic polysaccharide from Lycium barbarum L," Carbohydrate Polymers, vol. 147, pp. 114-124, 2016.

[28] J. Cheng, Z. W. Zhou, H. P. Sheng et al., "An evidence-based update on the pharmacological activities and possible molecular targets of Lycium barbarum polysaccharides," Drug Design, Development and Therapy, vol. 9, pp. 33-78, 2015.

[29] Q. Luo, Z. Li, X. Huang, J. Yan, S. Zhang, and Y.-Z. Cai, "Lycium barbarum polysaccharides: protective effects against heat-induced damage of rat testes and $\mathrm{H}_{2} \mathrm{O}_{2}$-induced DNA damage in mouse testicular cells and beneficial effect on sexual behavior and reproductive function of hemicastrated rats," Life Sciences, vol. 79, no. 7, pp. 613-621, 2006.

[30] Q. Luo, J. Li, X. Cui, J. Yan, Q. Zhao, and C. Xiang, "The effect of Lycium barbarum polysaccharides on the male rats' reproductive system and spermatogenic cell apoptosis exposed to low-dose ionizing irradiation," Journal of Ethnopharmacology, vol. 154, no. 1, pp. 249-258, 2014.

[31] M. V. Varoni, S. D. Gadau, V. Pasciu et al., "Investigation of the effects of Lycium barbarum polysaccharides against cadmium induced damage in testis," Experimental and Molecular Pathology, vol. 103, no. 1, pp. 26-32, 2017.

[32] G.-J. Shi, J. Zheng, J. Wu et al., "Protective effects of Lycium barbarum polysaccharide on male sexual dysfunction and fertility impairments by activating hypothalamic pituitary gonadal axis in streptozotocin-induced type-1 diabetic male mice,” Endocrine Journal, vol. 64, no. 9, pp. 907-922, 2017.

[33] J. Guo, S.-X. Tao, M. Chen et al., "Heat treatment induces liver receptor homolog-1 expression in monkey and rat sertoli cells," Endocrinology, vol. 148, no. 3, pp. 1255-1265, 2007.

[34] Y. Zhang, H.-M. Sun, X. He et al., "Da-Bu-Yin-Wan and Qian-Zheng-San, two traditional Chinese herbal formulas, up-regulate the expression of mitochondrial subunit $\mathrm{NADH}$ dehydrogenase 1 synergistically in the mice model of Parkinson's disease," Journal of Ethnopharmacology, vol. 146, no. 1, pp. 363-371, 2013.

[35] Y. Zhang, X.-G. Gong, Z.-Z. Wang et al., "Overexpression of DJ-1/PARK7, the Parkinson's disease-related protein, improves mitochondrial function via Akt phosphorylation on threonine 308 in dopaminergic neuron-like cells," European Journal of Neuroscience, vol. 43, no. 10, pp. 1379-1388, 2016.

[36] Y. Zhang, X. G. Gong, H. M. Sun et al., "Da-Bu-Yin-Wan improves the ameliorative effect of DJ-1 on mitochondrial dysfunction through augmenting the Akt phosphorylation in a cellular model of Parkinson's disease," Frontiers in Pharmacology, vol. 9, p. 1206, 2018.

[37] M. Sun, L. Yang, R. I. Feldman et al., "Activation of phosphatidylinositol 3-kinase/Akt pathway by androgen through interaction of p $85 \alpha$, androgen receptor, and Src," Journal of Biological Chemistry, vol. 278, no. 44, pp. 42992-43000, 2003.

[38] H. Amagase and N. R. Farnsworth, "A review of botanical characteristics, phytochemistry, clinical relevance in efficacy and safety of Lycium barbarum fruit (Goji)," Food Research International, vol. 44, no. 7, pp. 1702-1717, 2011.

[39] M. Jin, Q. Huang, K. Zhao, and P. Shang, "Biological activities and potential health benefit effects of polysaccharides isolated from Lycium barbarum L." International Journal of Biological Macromolecules, vol. 54, pp. 16-23, 2013.

[40] S. S. Kwok, Y. S. Bu, A. C. Y. Lo et al., "A systematic review of potential therapeutic use of Lycium barbarum polysaccharides in disease," Biomed Research International, vol. 2019, Article ID 4615745, 18 pages, 2019.

[41] G. M. J. Costa, S. M. S. N. Lacerda, A. F. A. Figueiredo, M. C. Leal, J. V. Rezende-Neto, and L. R. França, "Higher environmental temperatures promote acceleration of spermatogenesis in vivo in mice (Mus musculus)," Journal of Thermal Biology, vol. 77, pp. 14-23, 2018.

[42] S. Danno, K. Itoh, T. Matsuda, and J. Fujita, "Decreased expression of mouse Rbm3, a cold-shock protein, in sertoli cells of cryptorchid testis," The American Journal of Pathology, vol. 156, no. 5, pp. 1685-1692, 2000.

[43] A. P. S. Hikim, Y. Lue, C. M. Yamamoto et al., "Key apoptotic pathways for heat-induced programmed germ cell death in the testis," Endocrinology, vol. 144, no. 7, pp. 3167-3175, 2003.

[44] H. Cai, Y. Ren, X.-X. Li et al., "Scrotal heat stress causes a transient alteration in tight junctions and induction of TGF- $\beta$ expression," International Journal of Andrology, vol. 34, no. 4, pp. 352-362, 2011.

[45] M. He, L. Wang, Y. Chen, T. Zhang, and J. Guo, "Effect of Wuziyanzong pill on levels of sex hormones, and expressions of nuclear- associated antigen Ki-67 and androgen receptor in testes of young rats," Journal of Traditional Chinese Medicine, vol. 36, pp. 743-748, 2016.

[46] Y. Pei, Y. Wu, and Y. Qin, "Effects of chronic heat stress on the expressions of heat shock proteins 60, 70, 90, A2, and HSC70 in the rabbit testis," Cell Stress and Chaperones, vol. 17, no. 1, pp. 81-87, 2012.

[47] M. Miettinen, I. Virtanen, and A. Talerman, "Intermediate filament proteins in human testis and testicular germ-cell tumors," The American journal of pathology, vol. 120, pp. 402-10, 1985.

[48] M. Sobecki, K. Mrouj, J. Colinge et al., "Cell-cycle regulation accounts for variability in Ki-67 expression levels," Cancer Research, vol. 77, no. 10, pp. 2722-2734, 2017.

[49] S. McCoard, T. Wise, D. Lunstra, and J. Ford, "Stereological evaluation of sertoli cell ontogeny during fetal and neonatal life in two diverse breeds of swine," Journal of Endocrinology, vol. 178, no. 3, pp. 395-403, 2003.

[50] F. E. Franke, K. Pauls, R. Rey, A. Marks, M. Bergmann, and K. Steger, "Differentiation markers of sertoli cells and germ cells in fetal and early postnatal human testis," Anatomy and Embryology, vol. 209, pp. 169-77, 2004. 
[51] X.-S. Zhang, Z.-H. Zhang, S.-H. Guo et al., "Activation of extracellular signal-related kinases 1 and 2 in sertoli cells in experimentally cryptorchid rhesus monkeys," Asian Journal of Andrology, vol. 8, no. 3, pp. 265-272, 2006.

[52] J. Fedder, "Prevalence of small testicular hyperechogenic foci in subgroups of 382 non-vasectomized, azoospermic men: a retrospective cohort study," Andrology, vol. 5, no. 2, pp. 248-255, 2017.

[53] D. D. Mruk and C. Y. Cheng, "The mammalian blood-testis barrier: its biology and regulation," Endocrine Reviews, vol. 36, no. 5, pp. 564-591, 2015.

[54] M. J. McCabe, C. F. Foo, M. E. Dinger, P. M. Smooker, and P. G. Stanton, "Claudin-11 and occludin are major contributors to sertoli cell tight junction function, in vitro," Asian Journal of Andrology, vol. 18, pp. 620-626, 2016.

[55] T. Nagano and F. Suzuki, "The postnatal development of the junctional complexes of the mouse sertoli cells as revealed by freeze-fracture," The Anatomical Record, vol. 185, no. 4, pp. 403-417, 1976.

[56] D. G. Cyr, L. Hermo, N. Egenberger, C. Mertineit, J. M. Trasler, and D. W. Laird, "Cellular immunolocalization of occludin during embryonic and postnatal development of the mouse testis and epididymis*," Endocrinology, vol. 140, no. 8, pp. 3815-3825, 1999.

[57] J. Gerber, K. Weider, N. Hambruch, and R. Brehm, "Loss of connexin43 (Cx43) in sertoli cells leads to spatio-temporal alterations in occludin expression," Histology and Histopathology, vol. 29, pp. 935-948, 2014.

[58] L. Chang, Z. Lu, D. Li et al., "Melamine causes testicular toxicity by destroying blood-testis barrier in piglets," Toxicology Letters, vol. 296, pp. 114-124, 2018.

[59] C. M. Van Itallie and J. M. Anderson, "Architecture of tight junctions and principles of molecular composition," Seminars in Cell \& Developmental Biology, vol. 36, pp. 157-165, 2014.

[60] B. E. Smith and R. E. Braun, "Germ cell migration across sertoli cell tight junctions," Science, vol. 338, no. 6108, pp. 798-802, 2012.

[61] G. Erkanli Senturk, Y. Ersoy Canillioglu, C. Umay, E. Demiralp-Eksioglu, and F. Ercan, "Distribution of zonula occludens-1 and occludin and alterations of testicular morphology after in utero radiation and postnatal hyperthermia in rats," International Journal of Experimental Pathology, vol. 93, pp. 438-449, 2012.

[62] M. Saitou, K. Fujimoto, Y. Doi et al., "Occludin-deficient embryonic stem cells can differentiate into polarized epithelial cells bearing tight junctions," Journal of Cell Biology, vol. 141, no. 2, pp. 397-408, 1998.

[63] R. Sharpe, C. McKinnell, C. Kivlin, and J. Fisher, "Proliferation and functional maturation of sertoli cells, and their relevance to disorders of testis function in adulthood," Reproduction, vol. 125, pp. 769-784, 2003.

[64] J. Regadera, F. Martinez-Garcia, P. Gonzalez-Peramato, A. Serrano, M. Nistal, and C. Suarez-Quian, "Androgen receptor expression in sertoli cells as a function of seminiferous tubule maturation in the human cryptorchid testis," Journal of Clinical Endocrinology \& Metabolism, vol. 86, no. 1, pp. 413-421, 2001.

[65] A. Willems, S. R. Batlouni, A. Esnal et al., "Selective ablation of the androgen receptor in mouse sertoli cells affects sertoli cell maturation, barrier formation and cytoskeletal development," PloS One, vol. 5, p. e14168, 2010.

[66] B. D. Manning and L. C. Cantley, "AKT/PKB signaling: navigating downstream,” Cell, vol. 129, no. 7, pp. 1261-1274, 2007.
[67] S. B. Meroni, M. N. Galardo, G. Rindone, A. Gorga, M. F. Riera, and S. B. Cigorraga, "Molecular mechanisms and signaling pathways involved in sertoli cell proliferation," Frontiers in Endocrinology, vol. 10, p. 224, 2019.

[68] P. Liu, Z. Wang, and W. Wei, "Phosphorylation of Akt at the C-terminal tail triggers Akt activation," Cell Cycle, vol. 13, no. 14, pp. 2162-2164, 2014.

[69] Y. Fan, Y. Liu, K. Xue et al., "Diet-induced obesity in male C57BL/6 mice decreases fertility as a consequence of disrupted blood-testis barrier," PloS One, vol. 10, p. e0120775, 2015.

[70] N. Lin, L.-F. Xu, and M. Sun, "The protective effect of trefoil factor 3 on the intestinal tight junction barrier is mediated by toll-like receptor 2 via a PI3K/Akt dependent mechanism," Biochemical and Biophysical Research Communications, vol. 440, no. 1, pp. 143-149, 2013.

[71] X. Liu, X. Zhang, K. Ma et al., "Matrine alleviates early brain injury after experimental subarachnoid hemorrhage in rats: possible involvement of PI3K/Akt-mediated NF-kappaB inhibition and Keap1/Nrf2-dependent HO-1 inductionn," Cellular and Molecular Biology (Noisy-Le-Grand, France), vol. 62, pp. 38-44, 2016.

[72] B. Mao, D. Mruk, Q. Lian et al., "Mechanistic insights into PFOS-mediated sertoli cell injury," Trends in Molecular Medicine, vol. 24, no. 9, pp. 781-793, 2018.

[73] Q. Deng, Z. Zhang, Y. Wu et al., "Non-genomic action of androgens is mediated by rapid phosphorylation and regulation of androgen receptor trafficking," Cellular Physiology and Biochemistry, vol. 43, no. 1, pp. 223-236, 2017. 